\title{
Inclusive Growth and International Labour Migration
}

\author{
Sergey Chepel $^{1}$, Evgenia Tukhtarova ${ }^{2,3}$, Natalia Neklyudova $^{2, *}$ \\ ${ }^{1}$ Institute for Forecasting and Macroeconomic Research, Tashkent, Uzbekistan \\ ${ }^{2}$ Institute of Economics, Ural Branch of the Russian Academy of Sciences, Russia \\ ${ }^{3}$ Ural State Economic University, Russia
}

\begin{abstract}
This contribution presents the results of an econometric analysis of the interconnections between migration, economic diversification, the quality of state institutions and other qualitative characteristics of economic growth that have developed in developing countries of the world over the past two decades. The study highlighted the most important factors that contribute to the creation of conditions and prerequisites for the inclusive development of the economy. The analysis showed that among other factors, the most important are the quality of state institutions, technological development, which creates the conditions for investing in human capital. The study also made it possible to determine thresholds for these factors as guidelines for the transition of the CIS countries to the inclusive development of their economies and to limit disordered labour migration. Another important result of the study is the fact that large-scale and poorly controlled migration is acting like a brake on the sustainable development of the whole post-Soviet space. To overcome this process, it is necessary to create large-scale joint integration, knowledge-based and technological projects that will not only reduce the scale of migration to Russia, but also contribute to increasing human capital in the CIS countries and to the creation of knowledge-based jobs in their labour markets.
\end{abstract}

Key words: labour migration; inclusive growth; income inequality; technological development; state institutions; human capital

\section{Introduction}

The problem of economic growth is a major topic of modern scientific discussion. As a fundamental point, it is not so much a return to high economic growth, but rather the formation of a new growth model that would be able to involve all available resources in the process. Moreover, this process would ensure the development of both state institutions and technological structures, as well as the comprehensive development and accumulation of human capital. This approach reflects the understanding that the wellbeing of society is derived not only from the growth of real GDP and the material income of the population, but is a multidimensional concept, including the accumulation of physical and human capital. It is also important to take into account the fact that the model should be based not only on one parameter of "sustainability" of economic growth, in modern realities this is no longer enough, but should be inclusive, that is, have a positive impact on the wellbeing of the general population.

The stagnation of the world economy in the context of fiscal constraints associated with the crises of globalization poses risks to sustained growth and employment. More households face the risk of poverty and poor access to education and medicine, which ultimately exacerbates inequalities between countries. As is known, high levels of inequality can lead to falling aggregate demand, loss of social stability and, ultimately, uncontrolled migration flows [33].

The growing inequality is caused not only by globalization, but also by uneven technological shifts across countries. For example, the combined impact of institutional and technological changes led to increased economic and social inequality in European countries as early as in the 1980s [1].

In this regard, it is becoming clear that the current model of development based on stimulating consumer demand and expanding production is no longer the basis for sustained economic growth. The continuation of this approach will have many undesirable social, economic and environmental consequences. To overcome modern challenges, a rethinking of theoretical and methodological approaches is necessary in order to develop a new solution to current problems. We believe that the concept of sustainable development (sustainable development is a concept based on the analysis of the nation's

\footnotetext{
* Corresponding author: nnp81@mail.ru
} 
assets, one of whose elements is human capital) needs to be refreshed and recognize a deeper consideration of the social dimension in linking the qualitative characteristics of human capital and economic growth.

The modern concept of inclusive economic growth, where the quality and role of human resources play a primary role, can offer options for overcoming the current crisis. This contribution presents the results of research into and solutions for the transition of the CIS countries towards inclusive growth.

In this contribution, "inclusive growth" refers to an approach based on the effective use of all available resources, especially the enhancement of the role of human capital and its innovative activities.

\section{Theoretical Review}

The scientific community has now developed three main paradigms for sustained economic growth:

1) the model of investment growth, which is based on a high level of capital investment in the development and implementation of technologies created in national economies [2];

2) the model of innovative growth - here growth, unlike the previous model, is embedded in "advanced innovations", the development of new technologies and their distribution outside national borders [3,4];

3) the inclusive growth model based on the effective use of human capital and innovative activities [5-7].

The first two models, based on the technological development of countries, ceased to provide growth in labour productivity. Although technological factors of production continue to play a role in labour productivity, human resources and the quality of institutions in a country are becoming increasingly important [8]. So, according to foreign researchers, a country's growth can be attributed to inclusivity if the following condition is met: if simultaneously with the increase in a country's GDP there is an increase in the human development index (HDI) [9]. In this case, the role of the state in achieving the balance between investment policies and the development of the national innovation system is increasing.

Labour migration, which is an integral part of the labour market, can both increase the inclusiveness of a country's economic growth and contribute to its decline in world ratings for this indicator.

The effect depends on the immigrants' qualifications and skills. The influx of foreign unskilled workers can lead to an increase in the supply curve for labour and an increase in investment in physical capital. On the other hand, labour migration can affect not only the level of physical capital, but also the sectoral distribution. Thus, the arrival of highly skilled immigrants in a country causes the growth of knowledge-intensive industries and contributes to sustainable, inclusive economic growth [10], whereas the influx of low-skilled immigrants helps to attract capital to labour-intensive medium and low-tech sectors of the economy, which can stagnate it due to the intensive operation of infrastructure without modernizing it. In other words, capital is replaced by work and the development of a country is being carried out at the expense of extensive sources.

Uncontrolled illegal and disordered migration unambiguously has negative consequences. Diaz, Saenz and Kwan showed that the influx of Mexican illegal migrants in Arizona over four years (2006-2009) led to an increase in unemployment amid stagnant economic growth in this state [11]. The negative link between illegal migration and economic growth is due to the fundamental basis of social inequality and the decline in a country's inclusive potential. This is due to the need to direct budget flows not to socio-economic development, for example, healthcare or education, but to ensure law and order and strengthen law enforcement agencies in the country.

The impact of labour migration on the budget is reflected not only in the tax revenues from migrant labour, but also in the need for their integration and social benefits. Moreover, immigration affects transfer payments, increasing the burden on the financial sphere due to the difference in interest rates between the local population and foreigners, as a result of which there is an inadequate redistribution of the country's financial resources, and as a result - a decrease in the quality (inclusiveness) of growth. According to the survey by Kerr and Kerr [12], based on retrospective studies, on average the state budget has a slight positive net financial effect for host countries. At the same time, the large influx of unskilled labour seriously limits the country's high-quality (inclusive) development. This is confirmed by other studies. For example, Mayr also estimated a small positive overall financial effect of migration processes on Austria's budget [13].

If the influx of skilled personnel has a positive impact on economic growth in the country of arrival, the sending state remains in a difficult position. Numerous studies on the outflow of human capital indicate a negative impact on the overall level of intellectual development of sending countries and on the qualitative indicators of economic growth. In particular, the study by Beine, Docquier and Rapoport [14] showed that large-scale outflows of skilled labour even in the medium term have a negative impact on the development of certain sectors of the economy in the sending country. At the same time the long-term impact of the outflow of skilled personnel is reflected in changes in the quality and quantity of human capital in the country of migrants' origin. As a result, this launches a negative multiplier effect, reducing the scientific and economic (that is inclusive) potential of the country. 
The heterogeneous effect of labour migration on economic growth is evidenced in other studies [15-17]. For example, Bildirici et al. established a positive link between migration and economic growth, which can be fair for importing countries, while for sending countries this link can be reversed [15]. This result was obtained for 77 countries between 1990 and 2001. In our opinion, this may be explained by the fact that in a situation of redundancy of human resources, the released places in the labour market reduce the burden on it. At the same time, state institutions can distribute the remaining human resources in the labour market more efficiently and on an even basis. For developed countries, this burden is increasing, leading to an imbalance between the labour market and productive forces. Due to the presence of strong state institutions in the country that are able to effectively manage the availability of resource potential, prerequisites for inclusive growth are created. While in other countries, state institutions that cannot cope with the imbalance in the country, leads to a decrease in the qualitative components of economic growth.

In countries with strong institutions, the inflow of migrant workers is manageable and even selective. In addition to the fact that developed countries allocate quotas for attracting the number of migrants, state institutions also calculate the number of necessary specialists in various sectors. This ensures both equilibrium in the labour market and increased quality growth in these sectors.

A number of other studies also show the important role of existing state institutions in a country, through which countries can benefit from migration processes and have a positive effect on poverty reduction and income growth in the country of origin. Thus, studies conducted at different times by foreign authors for individual countries recorded such a relationship through the following simplified mechanism of state regulation of migration processes:

"labour migrants $\rightarrow$ remittances $\rightarrow$ consumption growth $\rightarrow$ production growth $\rightarrow$ economic growth" [16, 18-20].

Consequently, the relationship between poverty and migration is a rather complex economic process, which is important to manage and for which strong, high-quality state institutions are required.

In the absence of such institutions, migration and its impact on economic growth can be reversed. So, there are research results of various authors with the opposite effect of remittances for the country. For example, Catrinescu et al. [21] noted that remittances can increase long-term economic growth only in countries where there is public confidence in the management decisions of state institutions. In countries with low-quality public institutions, usually with low incomes, the positive effect is observed only in the medium term. For example, this conclusion was made by Goschin [22] and Ziesemer [23] when investigating the impact of migration on economic growth in countries with an average income of less than $\$ 1,200$ per capita. Other researchers came to the same conclusion, explaining this effect by the fact that, despite the positive impact of remittances on economic growth and the reduction of poverty in the country of the migrant exodus, they are sources of external shocks in the event of crises in the world economy and, as a result, lead to the instability of economic development [24].

Another explanation of the feedback between migration and economic growth is that a sharp increase or decrease in remittances can have a strong negative effect of weakening a country's trade balance and reducing its competitiveness in foreign markets $[25,26]$.

Numerous recent studies show that in developing countries, a large proportion of remittances of migrants sent home are not always invested in the productive needs of the country. For example, in poor countries, remittances are often used to repay household loans and debts, bypassing the mechanism for transforming money into investment [21, 27-29].

The study by Anderson and Kroeger on the example of migrants from Kyrgyzstan also testifies to the fact. During the study, the authors recorded the positive impact of migration on the country's economic growth only in 2001-2008 [30]. However, even for the period from 2009 to 2011 the scientists noted that this potential was exhausted due to the deterioration of the country's human capital. Thus, the high rate of migration of skilled personnel led to the depletion of the human capital of Kyrgyzstan and worsened the country's economic development indicators in subsequent years. This can be explained by the fact that remittances were not invested in the human capital of young generations or in the country's economy. Since most of these transfers were directed to household personal consumption, this predetermined the decline in the country's economic potential. In this case, the country falls into the "poverty trap".

The phenomenon of the "poverty trap" was revealed by Lucas [31]. On the example of a study of various countries, Lucas showed that only a country that was able to direct investment effectively not only in physical but, first of all, in human capital can make a significant breakthrough in its development. The researcher has amply demonstrated, through successful countries, how investment in human capital creates a long-term link between technology and sustained economic growth.

Thus, empirical research shows the importance of migration processes in explaining the dynamics of economic growth. At the same time, the most important constraints to inclusive growth are weak state institutions, the poor quality of human capital and imbalances between productive forces and the availability of labour in a country. All that leads to unsustainable economic growth.

Inequality in the development of countries is largely explained by the degree of access to education. As numerous studies show, the level of education is a very important prerequisite for the formation of conditions for the inclusive 
development of a country, as it creates the basis for the development of technology, which in turn is the basis for an inclusive leap into the future [32].

In 2016, Russia was the third largest recipient of migrants in the world, after the United States and Germany. The processes taking place in the world are also reflected in Russia. This is large-scale, poorly controlled migration, with poor quality state institutions, and economic development based on a raw-material orientation. While developed countries are currently transiting to the sixth digital technology architecture, Russia (in the presence of high human potential) lacks other prerequisites for the inclusive leap into the future. This is caused by the poor quality of its institutions and the lack of a balanced investment policy for the development and accumulation of physical and migration potential, as well as the creation of sustainable, adequately paid jobs in new sectors of the economy. A balanced and well-thought out migration policy with the participating countries is necessary for the transition towards inclusive sources of development. To this end, we propose investigating the impact of migration on inclusive development, based on the experience of successful countries.

\section{Methodology}

To examine the relationship between the qualitative characteristics of economic growth and the rate of migration in the current stage of economic development, an econometric study based on World Bank data for 76 developing countries was conducted. Countries with unstable political regimes, low incomes per capita (according to the per capita GDP criterion), as well as countries with a population of less than 5 million people were excluded from the category of developing countries.

The following indexes were chosen as indicators of economic development and inclusiveness: GDP per capita according to PPP at constant prices in 2011, the inclusive development index, the Gini coefficient and the human development index. World Bank data were used to estimate migration: the share of net migration in percentage (\%) of the local population, as well as UN data: net migration on average for five-year periods and the number of migrants in percentage (\%) of the local population. In addition to these indicators, the most important factors of inclusive development were also included: the quality of state institutions, indicators of economic diversification and scientific and technological development, the investment climate and labour market indicators (see Table 1). The statistical database developed in such a way made it possible to assess the link between migration and inclusive development, as well as to identify factors that play a critical role in sustained economic growth.

Table 1. Classifier of variables

\begin{tabular}{|c|c|}
\hline Variable & Explanation \\
\hline \multicolumn{2}{|c|}{ a. Level of economic development and inclusiveness (quality) of growth } \\
\hline gdp_pc_ppp & GDP per capita for PPPs in USD \\
\hline idi & Inclusive Development Index (ranging from 1 to 10 ) \\
\hline gini & Gini coefficient \\
\hline hdi & Human development index \\
\hline \multicolumn{2}{|r|}{ b. Migration } \\
\hline nmigr & $\begin{array}{l}\text { Net migration (\% of the population using WB statistics - average estimates over five } \\
\text { years) }\end{array}$ \\
\hline nm95-00 (nm00-05,....) & $\begin{array}{l}\text { Net migration according to the UN estimates for } 1995-2000,2001-2005,2006-2010 \text {, } \\
2011-2015 \text { (in thousands people) }\end{array}$ \\
\hline nm00-15pop & Ratio of net migration (by $\boldsymbol{n m 0 0 - 1 5}$ indicator) to population \\
\hline nmbmigr & $\begin{array}{l}\text { Number of migrants ( } \% \text { of the population, from the UN International Migration } \\
\text { Report 2015) }\end{array}$ \\
\hline \multicolumn{2}{|r|}{ c. Employed in labour markets } \\
\hline empl & Employment rate in $\%$ of the population \\
\hline emp_ind & Employed in industry (\% of total employment) \\
\hline \multicolumn{2}{|r|}{ d. Quality of state institutions } \\
\hline rol & Rule of Law Index \\
\hline cpi & Corruption perceptions index (from 0 to 100 , average for 2012-2015) \\
\hline goveff & Government efficiency \\
\hline \multicolumn{2}{|c|}{ e. Economic diversification and scientific and technological development } \\
\hline manuf & Manufacturing (\% of GDP) \\
\hline htexport & High-tech exports (\% of manufacturing export) \\
\hline intus & Internet users (per 100 people) \\
\hline patapp & Patents (residents per 1 million people) \\
\hline r\&dexp & Expenditures for R\&D (\% of GDP) \\
\hline publ & Number of publications in scientific journals per 1 million people \\
\hline labter & Number of employees with higher education $(\%)$ \\
\hline
\end{tabular}




\begin{tabular}{|l|l|}
\hline \multicolumn{1}{|c|}{ Variable } & \multicolumn{1}{c|}{ Explanation } \\
\hline yearter & Number of years of university education \\
\hline \multicolumn{2}{|c|}{ f. Investment activity and resource endowment } \\
\hline fdi & Net inflows of foreign direct investment (\% of GDP) \\
\hline inv & Gross fixed investment (\% of GDP) \\
\hline res & Resource endowment of a country (1- resource-rich, 0 - other countries) \\
\hline
\end{tabular}

Note: specific values of variables are given in the annual average for the period of 2000-2017.

Source: Authors.

In order to select the indicators of migration flows that reflect economic processes more effectively, statistical tests were conducted on their adequacy and reliability. The quantitative analysis and testing yielded the following results:

1) Number of migrants (in \% of the population, from the UN International Migration Report 2015, nmbmigr) - an indicator reflecting the number of registered migrants living in the territory of the country, showed that for the absolute majority of countries (50 countries out of 73 that have relevant statistics for this indicator, see figure with histogram for nmbmigr) its value is less than $5 \%$. This means that most developing countries are labour service providers. The advantage of this indicator, unlike the other two, is that its value is positive, which facilitates the interpretation of the results of regression analysis. The leading countries according to this indicator are UAE (81\%), Kuwait (70\%), Oman (41\%), Jordan (36\%), Saudi Arabia (29\%), etc. Among the CIS countries, Kazakhstan (20\%), Belarus (11\%) and Russia $(8 \%)$, i.e. the countries with the highest level of development (USD 17-24,000 per capita) in the post-Soviet space, differed due to the high level of migration in recent years, which was one of the incentives for the influx of migrant labour. On the other hand, the number of migrants in Central Asian countries was less than 5\% (Tajikistan - 3\%, Uzbekistan 4\%, Kyrgyzstan - 5\%). This reflects their position as labour-exporting countries, formed by, among other things, the low level of development of their economies (USD 3-6 per capita) and therefore the low incomes of the population.
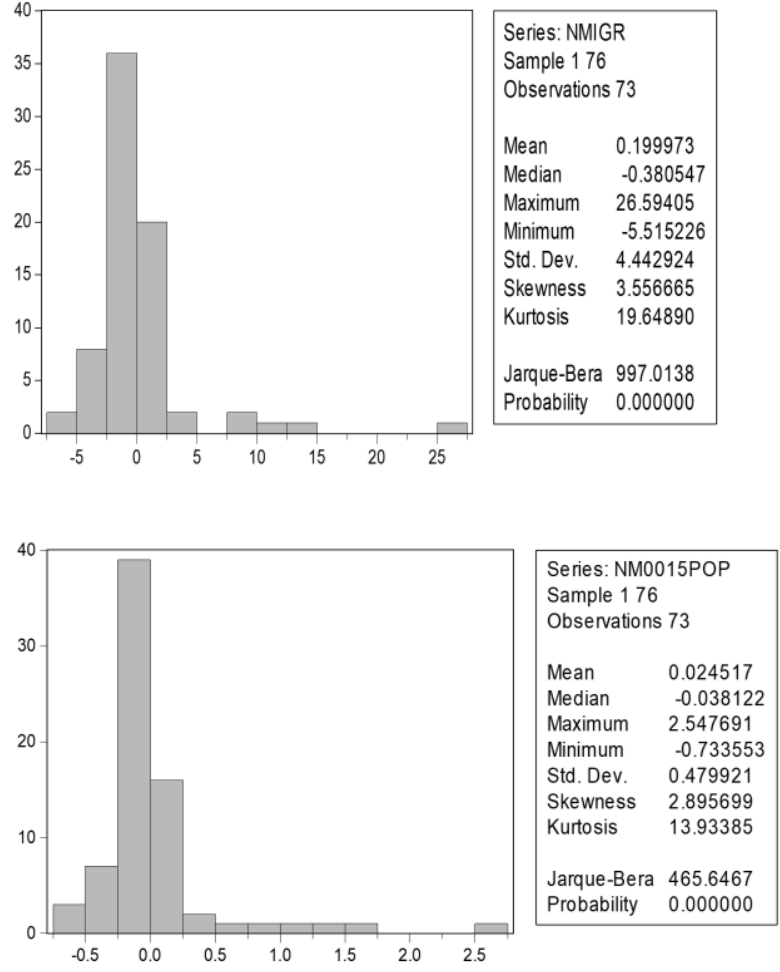

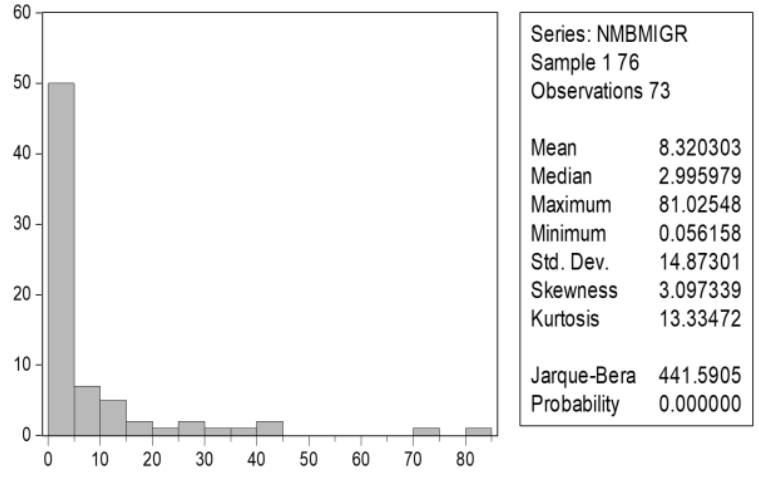

Migration indicators:

nmigr - net migration (\% of the population using WB statistics - average estimates over five years);

nmbmigr - the number of migrants in the country $(\%$ of the population, from the UN international migration report 2015);

nm95-00 (nm00-05,....) - net migration according to the UN estimates for 1995-2000, 2001-2005, 20062010, 2011-2015. (in thousand persons nm00-10pop per capita)

Figure 1. Distribution of studied states - countries with migrant inflows and outflows

Source: Authors.

2) The indicator of net migration (nmigr, in \% of the population according to World Bank statistics) varies in our sample of countries in the range from $5.5 \%$ to $26.6 \%$. The advantage of this indicator is that it makes it possible to separate countries with an inflow of migrants that exceeds their outflow (nmigr $>0$, countries that are consumers of foreign labour services) from countries that provide labour force $(\mathbf{n m i g r}<0)$. At the same time, the number of countries of the second category (48) significantly exceeds the number of the first group of countries (25). It should be noted that the leading countries with a maximum inflow of migrants are almost the same as for the previous indicator (nmbmigr): Kuwait (11.1\%), Malaysia (2.0\%), Oman (13.0\%), Saudi Arabia (3.4\%), etc. Among the CIS countries, net labour inflows in 
2000-2015 occurred in Russia (2.2\%), Kazakhstan and Belarus (0.1\%). At the other extreme, the leading labour exporting countries includes states that were part of the former USSR: Moldova $(-5.5 \%$ of the population, average estimate for 2000-2015), Georgia (-4.8\%), Armenia (-3.7\%), Lithuania (-3.6\%), Latvia (-2.8\%); as well as Albania (-5.5\%) and El Salvador (-4.8\%). For Central Asian countries, the values of this indicator were the following: Kyrgyzstan $-3.4 \%$, Uzbekistan $-1.7 \%$, Tajikistan $-1.2 \%$, with an average median estimate for developing labour exporting countries of $1.3 \%$.

3) The indicator of net migration according to UN nm00-10pop is similar in value to the World Bank nmigr indicator and differs only in the procedure for obtaining averaged estimates, as well as a higher average level of net migration ( $10.5 \%$ versus $1.3 \%$ for nmigr), which makes it preferable to the World Bank indicator.

The primary findings were as follows: although all indicators are based on existing statistical reporting (migrant registration) and significantly underestimate the actual absolute extent of migration, they all provide an objective picture of the differences across any of these indicators for the vast majority of developing countries in the world; the vast majority of them were migrant suppliers; only a small number of developing countries have a significant number of registered migrants (the first 5 countries account for half of all migrants). There is a strong statistically significant correlation between these three indicators (pairwise correlation coefficients from +0.85 to +0.95 ). All this proves the validity of the hypothesis discussed above and the possibility of using these indicators in further analysis.

Econometric methods were used to examine the relationship between these indicators. At the same time, the peculiarity of the matrix structure according to the indicators included in the analysis was taken into account. This consists primarily of matrices (indicators) of varying degrees for some sample countries. An example is omissions in the dynamics of indicators such as, among other things, spending on education, science and technology, the Gini coefficient, and the number of employees with higher education.

This makes it very difficult to use classical panel analysis methods (RE, FE, etc.). The only alternative in this case is the use of the cross-section method for averaged estimates of indicators (see Table 1) throughout the reporting period (2000-2015) and for all selected developing countries.

Both the traditional form of multifactor regression equations and the form with threshold values were used, which made it possible to substantiate the role and significance of state institutions in solving the problem of streamlining migration flows and improving the quality of economic growth for countries located in the post-Soviet space.

\section{Results} tested.

In order to investigate the link between migration and inclusive development, two hypotheses were formulated and

Hypothesis 1. The low-cost labour force created by disordered large-scale labour migration is a deterrent for developing countries, preventing the diversification of their economies and the growth of scientific and technological potential (the analogue of the resource curse hypothesis).

Based on the information opportunities provided by the resources of the World Bank, the United Nations and other international organizations (see variable classifier, Table 1), the indicator of the level of development of the manufacturing industry was used to test the hypothesis. This indicator generally correlates well with the breadth of the range of products produced (level of diversification) and is an indicator of the share of high-tech products in a country's exports. The control variables were indicators of investment activity, the quality of state institutions, number of employees, and the quality of human capital.

The result of searching for a large number of combinations of control variables with migration factors (nmigr, nmbmigr, nm00-15) showed (see Table 2) that the indicator of economic diversification manuf is statistically significantly associated with the migration factor nmbmir (number of migrants in $\%$ of the population). In all the obtained regressions (Nos. 1-3 in Table 2), the corresponding coefficient has a stable negative value for various combinations of control variables (share of employees in manufacturing industry, the quality of state institutions, resource endowment, etc.). This means that for countries with high levels of labour migrants (Kuwait, UAE and other OPEC countries, Russia, Kazakhstan, etc.) an increase in this factor reduces the level of diversification of the economy and enhances its commodity character, vulnerability to external shocks and instability of world markets. At the same time, an additional increase in net migration by 10 percentage points is associated with a decrease in the share of manufacturing industry (level of economic diversification) by an amount of 1.1 to 1.5 percentage points.

A similar equation was obtained for the indicator of technological development (share of high-tech products in exports (htexport), equation 4). The number of migrants (nmbmig) shows a negative impact on this indicator, while the effectiveness of the government and the number of employed in the economy (in \% of the population) increases the level of technological development. These results are the arguments in favour of the hypothesis under consideration. 
It is important to note another result of econometric analysis. In almost all the regressions obtained, the control variables included factors characterizing the qualitative component of economic development - government efficiency (goveff) and the quality of human capital (hdi). In terms of content, this may mean not only that these factors are important for the development of finished-product industries, but also that these indicators can influence the quality of migration flows, their orderliness and ultimately their reduction.

Table 2. Econometric assessment of migration impact on economic diversification and technological development

\begin{tabular}{|c|c|c|c|c|}
\hline \multirow{2}{*}{ Explaining variable (factors) } & \multicolumn{3}{|c|}{ Dependent variable - manuf (manufacturing) } & \multirow{2}{*}{$\begin{array}{l}\text { Dependen } \\
\text { variable } \\
\text { htexport } \\
\text { № } 4 \\
\end{array}$} \\
\hline & № 1 & № 2 & № 3 & \\
\hline $\begin{array}{l}\text { Control variables } \\
\text { Employed in industry (emp_ind) }\end{array}$ & $0.036^{* * *}$ & $0.27^{* * *}$ & $0.22^{* *}$ & \\
\hline Government efficiency (goveff) & & $2.46^{* *}$ & & $9.61^{* * *}$ \\
\hline $\begin{array}{l}\text { Resource endowment of a country } \\
\text { (resdummy) }\end{array}$ & & -2.15 & -1.75 & \\
\hline $\begin{array}{l}\text { Corruption perceptions index in resource- } \\
\text { rich countries } \\
\text { (res*cpi) }\end{array}$ & & & & -0.39 \\
\hline Human development index (hdi) & & & $0.13^{* *}$ & \\
\hline $\begin{array}{l}\text { Human development index in resource- } \\
\text { rich countries } \\
\text { (res*hdi) }\end{array}$ & & & & 0.18 \\
\hline Employed in economy (empl) & & & & $0.34^{* * *}$ \\
\hline Number of migrants (nmbmigr) & $-0.11^{* * *}$ & $-0.15^{* * *}$ & $-0.14^{* * *}$ & $-0.17^{*}$ \\
\hline Constant & 8.78 & 11.4 & 4.50 & -6.8 \\
\hline $\mathbf{R}^{2}$ & 0.24 & 0.32 & 0.31 & 0.25 \\
\hline Number of countries & 73 & 73 & 72 & 71 \\
\hline
\end{tabular}

Note: $* * *$ - significant at $1 \%, * *-5 \%, *-10 \%$.

Source: Authors.

The conclusions above find additional confirmation when moving from the traditional form of multifactorial regression equations to regressions with threshold values. Most often, the use of such regressions is aimed at determining the threshold value of the quality of state institutions, the excess of which creates conditions for a positive and statistically significant effect of one of the control variables on the dependent variable, while improving the quality of the entire equation. The form of the regression equation in this case is the following:

$$
\operatorname{div}=c+a_{1} * \operatorname{migr}+a_{2} * C V_{1}+a_{3} * C V_{2}+\ldots+b *(t h-Q I) * C V_{3}
$$

where $\boldsymbol{d i v}$ is an indicator of the level of economic diversification (or its technological development);

$\boldsymbol{Q I}$ - quality indicator of state institutions (corruption perceptions index - cpi, government efficiency - goveff, etc.);

$\boldsymbol{C} \boldsymbol{V}_{1,2 \ldots}$ - control variables (inv - investment, $\boldsymbol{r e s}$ - conditional variable for countries rich in natural resources, empl employed in economy, etc.);

$\boldsymbol{c}$ - constant, $\boldsymbol{a}_{1,2 \ldots \boldsymbol{b}} \boldsymbol{b} \boldsymbol{t h}$ - econometrically estimated regression coefficients, including the threshold value for the quality of state institutions $(\boldsymbol{t h})$.

If the results of the regression parameter assessment show the negativity and significance of coefficient $\boldsymbol{b}$, as well as a positive and significant estimate of parameter $\boldsymbol{t h}$, then the growth of factor $\boldsymbol{C} \boldsymbol{V}_{3}$ will lead to an increase in the diversification of the economy (dif) only when the state institution quality indicator $(\boldsymbol{Q} I)$ for a particular country exceeds the threshold value $(\boldsymbol{t} \boldsymbol{h})$ obtained from the evaluation of the equation.

Based on the results of testing this form of relationships, two equations were obtained. The first shows the conditions for growth of diversification according to the indicator of the share of manufacturing industry in the structure of the economy and has the following form:

$$
\text { manuf }=10.37-0.13 * n m b m i g r+0.32 * i m p \_i n d-0.013 * f d i *(52.0-c p i)
$$




$$
\begin{aligned}
& \text { P-val (0.0017) (0.0003) } \\
& \mathrm{R}^{2}=0.30
\end{aligned}
$$

where the values of confidence probability (p-val) are given under each coefficient of factors included in the model. Since they are less than 0.1 , all these coefficients, and therefore the corresponding relationships, are statistically significant.

In this equation, the foreign direct investment indicator $(f d i)$ is the new control variable, while the corruption perceptions index (cpi) is an indicator of the quality of state institutions. The threshold value obtained $(\boldsymbol{t h}=52.0 \%)$ can be interpreted as follows: the inflow of foreign direct investment contributes to the diversification of the economy only if the value of this index exceeds $52 \%$ (in this case, the expression in brackets becomes negative and when multiplied by the negative value of the coefficient $\boldsymbol{b}=-0.013$ causes a positive increase in manuf with $\boldsymbol{f d i}$ growth).

It is noteworthy that the CIS countries do not meet this requirement and have estimates of this indicator significantly below the required threshold (for example, for Russia 28\%, Uzbekistan 18, Tajikistan 23, Kazakhstan 28, Kyrgyzstan 26, Azerbaijan 28, Belarus $31 \%$ ). This largely explains the lack of progress in diversifying the economies of these states, even in the face of the significant inflows of foreign direct investment that have taken place in these countries over the past 15 years. In the obtained equation, as in the above, the migration factor $\boldsymbol{n m i g r}$ has a negative impact on the level of diversification of the economy.

The second equation obtained gives a similar result for another indicator - the share of high-tech products in the export structure htexport (see equation below). The migration factor $\boldsymbol{n m b m i g r}$ is also negatively associated with a dependent variable in it. All this argues for the hypothesis we are considering that large-scale and irregular labour migration has a negative impact on economic diversification and technological development in our sample of developing countries.

$$
\begin{aligned}
& \text { htexport }=-9.75-0.16 * \text { nmbmigr }+0.35 * \text { empl }+4.24 * \text { goveff }-0.033 * \text { fdi } *(30.1 \mathrm{cpi}) \\
& \text { P-val } \quad(0.1) \quad(0.008) \\
& \mathrm{R}^{2}=0.30
\end{aligned}
$$

To create the necessary conditions for inclusive growth in developing countries, including states in the post-Soviet space, a second hypothesis was formulated and tested.

Hypothesis 2. The main factors in reducing disordered large-scale labour migration for developing countries are active investment policies, improved quality of government institutions and inclusive economic growth.

To test this hypothesis and apply the experience of these countries for the post-Soviet space, a subset of countries with negative net migration (49 countries) was allocated from the total number of developing countries (76 states).

Dependent variables in this case, unlike the equations obtained and described above, are migration indicators for labour exporting countries (nmigr, nm0015pop), the values of which, for the convenience of interpreting the results, are taken in terms of absolute values, i.e. with a plus sign. Indicators of investment activity (inv, fdi), quality of state institutions (cpi, rol, goveff) and of the inclusiveness of economic growth (gini, idi, emp_ind, manuf) were used as factors for reducing disordered migration. The level of economic development ( $\left.\boldsymbol{g} \boldsymbol{d} \boldsymbol{p} \_\boldsymbol{p} \boldsymbol{c} \boldsymbol{p p p}\right)$ and scientific and technological development ( $\boldsymbol{r} \&$ dexp, patapp, etc.) were used as control variables.

A large number of variants of these variables showed that the highest values of the statistical significance of interrelationships are achieved when using the nm0015pop indicator (UN indicator) as a dependent variable. Another condition identified in the course of the analysis is the use of regression with a threshold value on the quality indicator of state institutions, which gives better results than traditional multifactor regressions.

The obtained regression with the best statistical characteristics has the following form:

$$
\begin{aligned}
& \text { nm0015pop }=-0.34-0.14 * \text { r\&dexp- } 0.008 * \text { emp_ind }-0.001 * \mathrm{fdi}^{*}(25.2-\text { cpi }) \\
& \begin{array}{llll}
\text { P-val } & (0.09) & (0.05) & (0.01)
\end{array} \\
& \mathrm{R}^{2}=0.31
\end{aligned}
$$

All factors included in the regression are statistically significant (since $p$-val $<0.1$ ), and negative signs of coefficient values indicate a decrease in migration when the factor grows.

The result makes it possible to draw a number of important conclusions for measures to limit disordered migration. Firstly, the growth of investment activity (according to the foreign direct investment $\boldsymbol{f d i}$ indicator) does limit the scale of irregular migration, but only if one of the most important indicators of the quality of state institutions - corruption perceptions index cpi - exceeds the econometrically obtained threshold of 25.2 (on a 100-point scale). This result is well 
within the earlier conclusion on indicators of diversification and technological development (manuf, htexport), although the previously obtained thresholds were slightly higher (30 and 52).

As shown above, the average annual estimates of this indicator for the CIS countries (labour exporters) that we analysed range from 18 (Uzbekistan) to 26 (Kyrgyzstan), i.e. on the border or even below this threshold. Consequently, unless Central Asian governments take decisive measures to combat corruption, all efforts to stimulate investment to create new jobs and thereby limit migration to Russia and other countries with significantly higher labour costs will not yield the expected results, since the investment resources attracted will be used extremely inefficiently.

As for the hypothesis of the importance of inclusive economic growth to limit labour outflows, it was not fully confirmed. Using the idi (Inclusive Development Index, introduced by Asian Development Bank, is an annual assessment of 103 countries' economic performance that measures how countries perform on eleven dimensions of economic progress in addition to GDP. It has 3 pillars; growth and development; inclusion and; intergenerational equity sustainable stewardship of natural and financial resources) indicator as an inclusion factor shows its strong statistical insignificance $(\mathrm{p}$-val $>0.9)$. A similar result is characteristic of the Gini index.

Slightly better statistical estimates are obtained using combinations of these factors with the conditional variable res (country endowment of natural resources), i.e. in the form of $\boldsymbol{i d i} *$ res. In this case, p-val decreases to 0.3 but does not reach the required threshold value (0.1). This result can be interpreted as saying that inclusive development plays a special role for countries with rich natural resources.

Significance appears only when the variable of the proportion of employed in industry (emp_ind ) is used as an inclusion factor. While not strictly an indicator of inclusiveness, this variable nevertheless reflects the process of improving the quality of economic growth, since in developing countries, as the experience of China, Turkey and Malaysia shows, the contribution of economic growth to the expansion of sustainable and adequately paid employment is primarily associated with the creation of new jobs in non- extractive industries.

The analysis also showed that the most stable factor in all their combinations included in the regression was the factor of expenditure on R\&D ( $\boldsymbol{\&} \boldsymbol{d} \boldsymbol{d e x p})$. This underlines the importance of organizing joint integration projects between Russia and Central Asian countries in the field of research and development to limit irregular migration, which will create a significant number of new jobs in the field of medium- and high-tech industries that have a significant multiplier effect on the entire economy in terms of generating new employment.

\section{Conclusion}

The tested logical interrelationships and hypotheses made it possible to form guidelines for inclusivity for the postSoviet space. The analysis showed that the most important condition for inclusive development is the quality of state institutions. In this case, state institutions in the countries of the post-Soviet space need to create conditions for the effective management of migration processes. In our opinion, to increase the inclusiveness of economic growth in labour exporting countries, such as CIS countries, it is necessary to prioritise the creation of conditions for accelerating the development of manufacturing industry.

As world experience shows, the development of manufacturing industry depends heavily on the quality of education in a country. In this case, investment in human capital has an important role to play. The gap in income between CIS countries is also explained by the difference in quality indicators of human potential. Therefore, in order to equalize income between countries, it is necessary to create unified educational standards and interstate centres of competence, the directions of which correspond to the selected priorities of technological development in the countries of the postSoviet space.

Sharing technological experience is one of the most important conditions for increasing inclusiveness in the world. Therefore, it is necessary to move to a unified technological policy focused on the joint creation of unified technological platforms in key areas of economic activity for the CIS countries (resource conservation, transport, medicine, new materials, information technology, banking systems, etc.). The implementation of a unified technology policy will allow the CIS countries to reduce costs in the transition to the production of new generations of equipment and consumer products, as well as reduce the degree of scientific and technological dependence on western countries and China.

To implement a unified technological policy, it is necessary to create joint integration interstate projects, which, in addition to the technological breakthrough, can significantly mitigate the problem of employment in countries that send migrant workers.

Trade in technology provides the basis for the harmonization of customs regulations, tax policies, accounting, as well as the simplification of procedures for resolving economic disputes and the creation of independent (transnational) judicial bodies to resolve emerging issues.

The successful implementation of the proposed measures requires the effective and coherent work of state institutions in the CIS countries. In our opinion, it is necessary to create a supranational structure that will regulate and direct this 
process to increase the inclusiveness of the entire post-Soviet space, thereby involving state institutions, business and society, which will ultimately allow all countries to become active participants in the development of the world economy.

\section{References}

1. T. V. Merkulova, Economic growth and inequality: Institutional aspect and modeling of the relationship. Mir Rossii. Sotsiologiya. Etnologiya. 19(2), 59-77 (2010)

2. R. Harrod, An Essay in Dynamic Theory. The Economic Journal. 49(193), 14-33, (1939)

3. H. Etzkowitz, L. Leydesdorff, The dynamics of innovation: from National Systems and "Mode 2" to a Triple Helix of university-industry-government relations. Research Policy. 29(2), 109-123 (2000)

4. P. Aghion, S. Durlauf, Handbook of economic growth. Amsterdam: Elsevier (2005)

5. T. McKinley, Inclusive Growth Criteria and Indicators: An Inclusive Growth Index for Diagnosis of Country Progress. ADB Sustainable Development Working Paper Series. No.14. - Mandaluyong City, Philippines, Asian Development Bank (2010)

6. A. R. Ramos, R. Ranieri, J. Lammes, Mapping Inclusive Growth. Working Paper, No.105, International Policy Centre for Inclusive Growth (2013)

7. R. Anand, S. Mishra, and S. J. Peiris, Inclusive Growth: Measurement and Determinants. [online]. Available at: https://www.imf.org/external/pubs/ft/wp/2013/wp13135.pdf (2013)

8. L. V. Smorgunov, The State, Cooperation and Inclusive Economic Growth. Vlast'. 11, 22-30 (2017)

9. A. Roy, Inclusive Growth through MFIs' Outreach in Assam. Asia Pacific Business Review. 7(3), 47-62 (2011)

10. S. V. Chepel, A. K. Bondarenko, Is external labour migration factor of economic growth. Econometric analysis and conclusions for the CIS. Journal of the New Economic Association. 4(28), 142-166 (2015)

11. P. Diaz, D. Saenz, V. Kwan, Economic Dynamics and Changes in Attitudes Toward Undocumented Mexican Immigrants in Arizona. Analyses Of Social Issues And Public Policy. 11(1), 300-313 (2011)

12. S. P. Kerr, W. Kerr, Economic Impacts of Immigration: A Survey. Harvard Business School Entrepreneurial Management Working Paper. (2008)

13. K. Mayr, The Fiscal Impact of Immigrants in Austria - A Generational Accounting Analysis. Empirica. 32(2), 181216 (2005)

14. M. Beine, F. Docquier, H. Rapoport, Brain drain and economic growth: theory and evidence. Journal of Development Economics. 64(1), 275-289 (2001)

15. M. Bildirici, S. Sunal, E. A. Alp, M. Orcan, Determinants of Human Capital Theory, Growth and Brain Drain: An Econometric Analysis for 77 Countries. Applied Econometrics and International Development. 5(2), 109-140 (2005)

16. H. Chen, I. Fang, Migration, social security, and economic growth. Economic Modelling. 32, 386-399 (2013)

17. C. Di Maria, E. Lazarova, Migration, Human Capital Formation, and Growth: An Empirical Investigation. World Development. 40(5), 938-955 (2012)

18. S. Diaz-Briquets, J. Perez-Lopez, Refugee Remittances: Conceptual Issues and the Cuban and Nicaraguan Experiences. International Migration Review. 31(2), 411-437 (1997)

19. C. Woodruff, R. Zenteno, Remittances and Microenterprises in Mexico. Latin American Economics. (2001)

20. M. Sana, D. Massey, Household Composition, Family Migration, and Community Context: Migrant Remittances in Four Countries. Social Science Quarterly. 86(2), 509-528 (2005)

21. N. Catrinescu, M. Leon-Ledesma, M. Piracha, B. Quillin, Remittances, Institutions, and Economic Growth. World Development. 37(1), 81-92 (2009)

22. Z. Goschin, Remittances as an Economic Development Factor. Empirical Evidence from the CEE Countries. Procedia Economics and Finance. 10, 54-60 (2014)

23. T. H. W. Ziesemer, Worker remittances, migration, accumulation and growth in poor developing countries: Survey and analysis of direct and indirect effects. Economic Modelling. 29(2), 103-118 (2012)

24. K. S. Imai, R. Gaiha, A. Ali, N. Kaicker, Remittances, Growth and Poverty: New Evidence from Asian Countries. Journal of Policy Modeling. 36(3), 524-538 (2014) 
25. P. Guha, Macroeconomic effects of international remittances: The case of developing economies. Economic Modelling. 33, 292-305 (2013)

26. E. Nyamongo, R. Misati, L. Kipyegon, L. Ndirangu, Remittances, financial development and economic growth in Africa. Journal of Economics And Business. 64(3), 240-260 (2012)

27. D. Mosse, S. Gupta, M. Mehta, V. Shah, J. Rees, K. Team, Brokered livelihoods: Debt, Labour Migration and Development in Tribal Western India. Journal of Development Studies. 38(5), 59-88 (2002)

28. O. Stark, J. Taylor, S. Yitzhaki, Migration, remittances and inequality. Journal of Development Economics. 28(3), 309-322 (1988)

29. A. Barguellil, M. H. Zaiem, M. Zmami, Remittances, Education and Economic Growth: A Panel Data Analysis. Journal of Business Studies Quarterly. 4(3), 129-139 (2013)

30. A. Kroeger, K. Anderson, Remittances and Children's Capabilities: New Evidence from Kyrgystan, 2005-2008 [online]. Available at: https://www.diw.de/documents/publikationen/73/diw_01.c.388327.de/dp1170.pdf (2011)

31. R. Lucas, Lectures on economic growth. Cambridge, Mass.: Harvard University Press (2002)

32. S. V. Chepel, N. M. Ibragimova, Economic Growth and Accessibility of Higher Education: Hypotheses, Channels, Interrelations and Its Importance For Developing Countries. Human capital and vocational education. 4, 4-16 (2016)

33. World Economic Forum, Global Risks Report 2016. [online]. Available at: http://www3.weforum.org/docs/GRR/WEF_GRR16.pdf (2016) 